\title{
Course Achievement and Students Attitudes Towards Statistics
}

\author{
Diana Šimić, Jelena Gusić, Lucija Žignić \\ University of Zagreb, Faculty of Organization and Informatics \\ Pavlinska 2, HR-42000 Varaždin, Croatia \\ diana.simic@foi.hr; jelena.gusic@foi.hr; lucija.zignic@foi.hr
}

\begin{abstract}
Objective of this research was to analyse change in attitudes towards statistics in graduate students attending their second course in statistics, and association between attitude towards statistics and course achievement. SATS-36 instrument, with six scales (Affect, Cognitive Competence, Value, Difficulty, Interest, and Effort) was translated into Croatian and data collection was conducted during the academic year 2018/19. Pre- Difficulty, with Cronbach's alpha equal 0.67, was the only scale with reliability below 0.7. Change in attitudes towards statistics were observed on all scales except Cognitive Competence. Students' feelings toward statistics were more negative at the end of the course, and they perceived statistics as more difficult than at the beginning of the course. On the other hand, students' perception of value of, as well as interest in, statistics increased. Perceived effort put into the course was higher than expected at the beginning. The only association between course achievement and pre-, post-, or change in attitude scales was between post- Effort and course achievement.
\end{abstract}

Keywords: Statistics education, SATS-36, Attitudes Towards Statistics, Course achievement.

\section{Introduction}

Recently there is a growing consensus that attitudes towards a course are equally important for knowledge application in the future life as competencies acquired in the course. Schau and Emmioğlu [1] argument that student attitudes will influence whether students will use acquired competences in a future life. Students with negative attitudes towards course are less likely to use course related competences in the future life than students with positive attitudes.

To measure attitudes toward statistics courses, in 1995 Schau et al. [2] designed the Survey of Attitudes Towards Statistics. The first version, known as SATS-28, had 28 items grouped in 4 scales: Affect, Cognitive Competence, Value and Difficulty. Affect refers to positive or negative feelings about statistics, Cognitive Competence refers to self-assessment of intellectual knowledge and skills related to statistics, Value refers to attitudes about the usefulness, relevance, and value of statistics in everyday life and Difficulty refers to attitudes about the difficulty of statistics as a subject. In 2003, Schau [3] issued a new version, SATS-36. In comparison to SATS-28, in the new version, 8 new items were added and grouped into two new scales: Interest and Effort. Interest indicates the level of individual interest in statistics and Effort indicates the amount of work the student expends to learn statistics.

Both surveys were used and validated in many countries, e.g. Serbia [4], Russia [5], USA [6], Netherlands [7], Italia [8], Switzerland [9], Estonia [10], Indonesia [11], and Turkey [12]. In Croatia neither SATS-28, nor SATS-36, were conducted prior to this research.

Objective of this research was to analyse change in attitudes towards statistics in graduate students attending their second course in statistics, and association between attitude towards statistics and course achievement. For the purpose of this research, SATS-36 was translated to Croatian and conducted during the academic year 2018/19.

\section{Materials and Methods}

Students' responses to Survey of Attitudes Toward Statistics (SATS-36) were collected during the first and the last week of the course Statistical Data Analysis at graduate study of Economics of Entrepreneurship at the Faculty of Organization and Informatics, University of Zagreb, during the academic year 2018/19. There were 55 students enrolled in the course, and 51 responded to both pre- and post- survey. Course achievement was recorded as sum of all points students made on course assessments (range 0 to 100). We did not try to validate the six factor structure using confirmatory factor analysis because 
target population is small, and we would need to conduct the survey in several consecutive years to achieve reasonably large sample size. Reliability of the six scales was assessed using Cronbach's alpha, with 0.7 set as a limit value [1]. We also inspected corrected item total correlations (CITC). Pre- and post-scores were compared using two-sided t-test. Association between attitude scores and course achievement was assessed using Pearson's correlation coefficient.

\section{Results}

Table 1 presents Cronbach's alpha for SATS-36 scales. For pre-scale Difficulty Cronbach's alpha was 0.67. Item "Statistics is a very technical subject." on pre-scale Difficulty was the only item with CITC $<0.2$. For all other scales Cronbach's alpha values were at least 0.7 , indicating good internal consistencies.

Table 1: Cronbach's alpha values.

\begin{tabular}{|l|l|l|}
\hline \multirow{2}{*}{ Attitude: } & \multicolumn{2}{|l|}{ Cronbach's alpha values } \\
\cline { 2 - 3 } & Pre- & Post- \\
\hline Affect & 0.84 & 0.85 \\
\hline $\begin{array}{l}\text { Cognitive } \\
\text { Competence }\end{array}$ & 0.86 & 0.81 \\
\hline Value & 0.87 & 0.85 \\
\hline Difficulty & 0.67 & 0.74 \\
\hline Interest & 0.92 & 0.88 \\
\hline Effort & 0.70 & 0.73 \\
\hline
\end{tabular}

Table 2: Descriptive statistics for pre-, post-, and change scores of attitude scale.

\begin{tabular}{|l|r|r|r|r|r|r|r|r|r|r|}
\hline \multirow{2}{*}{ Attitude } & \multicolumn{4}{|c|}{ Pre- } & \multicolumn{3}{c|}{ Post- } & \multicolumn{4}{c|}{ Change } \\
\cline { 2 - 12 } & Mean & Median & SD & Mean & Median & SD & Mean & Median & SD & p-value \\
\hline Affect & 4.94 & 5.00 & 0.71 & 3.48 & 3.33 & 1.26 & -1.45 & -1.50 & 1.27 & $<0.00001$ \\
\hline $\begin{array}{l}\text { Cognitive } \\
\text { Competence }\end{array}$ & 4.34 & 4.33 & 0.78 & 4.44 & 4.33 & 0.92 & 0.10 & 0.17 & 0.93 & 0.42530 \\
\hline Value & 3.98 & 3.89 & 0.93 & 4.90 & 4.89 & 0.96 & 0.92 & 0.89 & 0.98 & $<0.00001$ \\
\hline Difficulty & 4.87 & 5.00 & 0.92 & 3.11 & 3.00 & 0.81 & -1.76 & -2.00 & 1.04 & $<0.00001$ \\
\hline Interest & 3.50 & 3.25 & 0.91 & 4.30 & 4.00 & 1.31 & 0.80 & 0.50 & 1.39 & 0.00013 \\
\hline Effort & 4.96 & 5.00 & 0.61 & 5.84 & 6.00 & 0.78 & 0.89 & 1.00 & 0.84 & $<0.00001$ \\
\hline
\end{tabular}

Table 2 shows descriptive statistics for pre-, post-, and change scores off attitude scales. Range of values was 1 to 7 , thus 4 represents a neutral attitude. On average, at the beginning of the course students had negative scores on Interest, neutral on Value, and positive on Affect, Cognitive Competence, Difficulty, and Effort. At the end of the course, their attitudes stayed the same for Cognitive Competence, significantly decreased for Affect and Difficulty, and significantly increased for Value, Interest, and Effort. Course achievement points varied between 53 and 91, with mean 71.6, median 72, and standard deviation 9.2. Distribution was symmetric, unimodal.

Figures 1 and 2 display distributions of pre-and post- scores, and distributions of change in scores, respectively. 


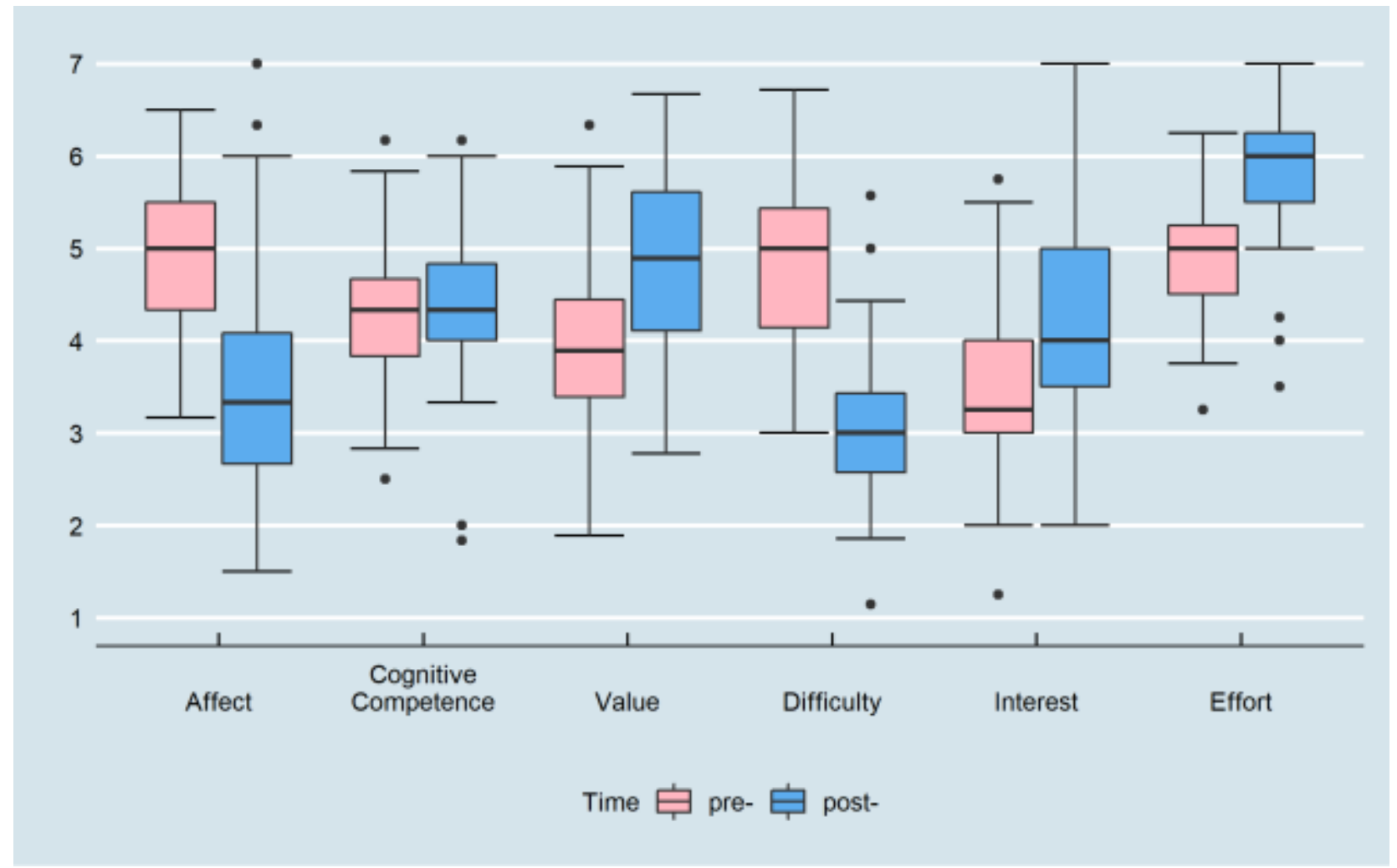

Fig. 1: Pre-and post-scores distributions of six SATS-36 attitude scales Affect, Cognitive Competence, Value, Difficulty, Interest, and Effort.

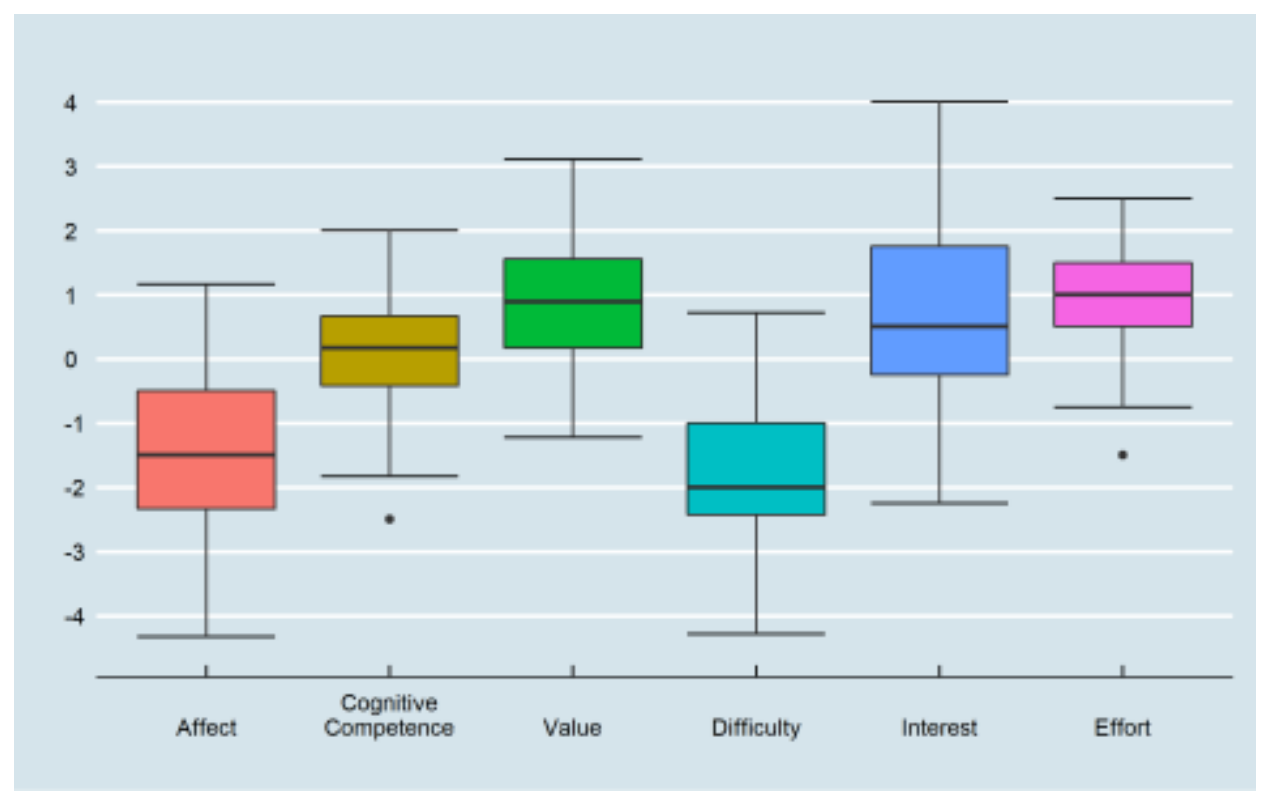

Fig. 2: Distributions of score changes for six SATS-36 attitude scales Affect, Cognitive Competence, Value, Difficulty, Interest, and Effort. 
There was no association between attitude scores at the beginning of the course and course achievement (correlations between 0 and 0.25 , none significant at $\mathrm{p}<0.05$ ). Correlation between attitude scores at the end of the course and course achievement varied between 0.06 and 0.31. Only the highest correlation (between Effort and course achievement) was statistically significant $(\mathrm{p}=0.025)$. There was no association between change in attitude scores and course achievement (correlations between -0.05 and 0.16 , none significant at $\mathrm{p}<0.05$ ).

\section{Conclusion}

Pre- Difficulty scale was the only scale that did not achieve Cronbach's alpha of at least 0.7 . This is consistent to findings of Tempelaar et. al. [7] on a similar population of students.

We have observed change in attitudes towards statistics on all scales except Cognitive Competence. For the Affect and Difficulty scales this change was negative, i.e. students' feelings toward statistics were more negative at the end of the course, and they perceived statistics as more difficult than at the beginning of the course. On the other hand, students' perception of value of, as well as interest in statistics increased, and effort put into the course was higher than expected at the beginning. In comparison to [1] and [13] our students had different attitudes at the beginning, and their change of attitude did not follow the same pattern. The only similarity is regarding increase in Effort as in [13], and no change of Cognitive Competence similar to [1]. Further research is needed in order to explain these differences.

The only association between course achievement and pre-, post-, or change in attitude scales was between post-

Effort and course achievement. This was to be expected, as higher effort should lead to better achievement.

We plan to continue collecting data in order to be able to test construct validity of the Croatian version of SATS-36.

\section{Acknowledgements}

We would like to thank Candace Schau, Phd., the copyright holder, for permission to use the SATS-36 instrument [3].

\section{References}

[1] C. Schau, E. Emmioğlu, "Do introductory statistics courses in the United States improve students' attitudes?" Statistics Education Research Journal, vol. 11, no. 2, pp. 86-94, 2012.

[2] C. Schau, J. Stevens, A. Del Vecchio, T. L. Dauphinee, "The Development and Validation of the Survey of Attitudes Toward Statistics," Educational and Psychological Measurement, vol. 55, no. 5, pp. 868-875, 1995.

[3] C. Schau. (2019, May 25). SATS-36 Scoring [Online]. Available: https://irp-cdn.multiscreensite.com/281322c3/files/uploaded/Final36scoring.pdf

[4] D. Stanisavljevic, G. Trajkovic, J. Marinkovic, Z. Bukumiric, A. Cirkovic, et al., "Assessing Attitudes towards Statistics among Medical Students: Psychometric Properties of the Serbian Version of the Survey of Attitudes Towards Statistics (SATS)," PLoS ONE, vol. 9, no. 11, 2014.

[5] T. Khavenson, E. Orel, M. Tryakshina, "Adaptation of survey of attitudes towards statistics (SATS 36) for Russian sample," Procedia - Social and Behavioral Sciences, vol. 46, pp. 2126 - 2129, 2012.

[6] S. B. Schou, "A Study of Student Attitudes and Performance in an Online Introductory Business Statistics Class," Electronic Journal for the Integration of Technology in Education, vol. 6, pp. 71-78, 2007.

[7] D. Tempelaar, S. S. van der Loeff, W. H. Gijselaers "A structural equation model analyzing the relationship of students' attitudes toward statistics, prior reasoning abilities, and course performance," Statistics Education Research Journal, vol. 6, no. 2, pp. 78-102, 2007.

[8] F. Chiesi, C. Primi, "Assessing statistics attitudes among college students: Psychometric properties of the Italian version of the Survey of Attitudes toward Statistics (SATS)," Learning and Individual Differences, vol.19, pp. 309313, 2009.

[9] D. Zimprich, “Attitudes Toward Statistics Among Swiss Psychology Students," Swiss Journal of Psychology, vol. 71, no. 3, pp. 149-155, 2012.

[10] C. Hommik, P. Luik, "Adapting the survey of attitudes towards statistics (SATS-36) for Estonian secondary school students," Statistics Education Research Journal, vol. 16, no. 1, pp. 228-239, 2017. 
[11] T. Prayoga, J. Abraham, "A psychological model explaining why we love or hate statistics," Kasetsart Journal of Social Sciences, vol. 38, pp. 1-8, 2017.

[12] E. Emmioglu Sarikaya, A. Ok, Y. Capa Aydin, C. Schau, "Turkish Version of the Survey of Attitudes toward Statistics: Factorial Structure Invariance by Gender," International Journal of Higher Education, vol. 7, no. 2, pp. 121-127, 2018.

[13] N. M. Milic, S. Masic, J. Milin-Lazovic, G. Trajkovic, Z. Bukumiric, M. Savic, et al., "The Importance of Medical Students' Attitudes Regarding Cognitive Competence for Teaching Applied Statistics: Multi-Site Study and MetaAnalysis," PLoS ONE vol. 11, no. 10, 2016.

[14] T. L. Dauphinee, C. Schau, J. J. Stevens, "Survey of attitudes toward statistics: Factor structure and factorial invariance for women and men,” Structural Equation Modeling: A Multidisciplinary Journal, vol. 4, no. 2, pp. 129-141, 1997.

[15] I. Persson, K. Kraus, L. Hansson, F. Yang Wallentin, "Confirming the Structure of the Survey of Attitudes Toward Statistics (SATS-36) by Swedish Students," Statistics Education Research Journal, vol. 18, no. 1, pp. 89-93, 2019. 